\title{
$\mathcal{A}$ Leitura do Texto Literário em Sala de Mula e o Conto "A Menina de Lá"I
}

\author{
Érica de Cássia Maia Ferreira RODRIGUES* \\ Naiane Vieira DOS REIS**
}

\begin{abstract}
* Doutoranda pelo Programa de Pós-Graduação em Ensino de Língua e Literatura - PPGL/UFT com bolsa CAPES. Mestre em Letras pelo Programa de Mestrado Profissional em Letras - PROFLETRAS/UFT. Membro do Grupo de Estudos do Sentido - GESTO/UFT. É formadora de professores da educação básica das redes municipais e estaduais. E-mail: ericadecassia@mail.uft.edu.br

** Doutora e Mestre pelo Programa de Pós-graduação em Letras: Ensino de Língua e Literatura, da Universidade Federal do Norte do Tocantins -UFNT. Atua no corpo editorial do periódico Entreletras, do campus de Araguaína, da UNFT. É formadora de professores das redes municipais e estaduais de educação básica. É professora substituta no Instituo Federal do Maranhão (IFMA), Campus São Luís - Monte Castelo. E-mail: naianevieira@uft.edu.br
\end{abstract}

\begin{abstract}
Resumo:
Este artigo discute sobre a formação literária na escola, considerando as orientações da Base Nacional Comum Curricular (BRASIL, 2018; 2019) que convergem para a formação de leitores não apenas do ponto de vista de saberes de natureza pragmática, mas, sobretudo, de ordem estética e sensível. Para isso, discorre sobre a leitura subjetiva, o desenvolvimento da capacidade de fruição, práticas pedagógicas e políticas de acesso às dimensões da arte. Analisa, ainda, o modo como a Base Nacional Comum Curricular, a despeito de destinar um campo para a literatura, deixa de conferir uma reflexão mais consistente sobre as especificidades que cercam a leitura do texto literário e o que pode ser desenvolvido na prática para a formação de leitores e leitoras de literatura. Mobilizamos estudos que tematizam a formação do leitor, o ensino de literatura e a semiótica greimasiana considerando categorias da sociossemiótica. Ao final, analisa-se um conto de Guimarães Rosa, considerando possibilidades de mediação para o ensino de leitura literária.
\end{abstract}

Palavras-chave:

Base Nacional Comum Curricular (BNCC); Ensino de literatura; Formação de leitores.

Signum: Estudos da Linguagem, Londrina, v.24, n2, p. 98-111, ago. 2021

Recebido em: 01/04/2021

Aceito em: 31/05/2021

\footnotetext{
1 Trabalho motivado pela disciplina "Seminários em Literatura de Língua Portuguesa e Ensino "Guimarães Rosa: Exercícios de transculturação" ministrada pela Profa. Dra. Betina Ribeiro Rodrigues da Cunha e Prof. Dr. Márcio Melo, no Programa de Pós-Graduação em Ensino de Língua e Literatura - PPGL, pela Universidade Federal do Tocantins -UFT, Campus Araguaína.
} 


\section{A Leitura do Texto Literário em Sala de Aula e o Conto "A Menina de Lá"}

Érica de Cássia Maia Ferreira Rodrigues; Naiane Vieira dos Reis

\section{INTRODUÇÃO}

Ler, apropriar-se dos livros, é reencontrar o eco longínquo de uma voz amada na infância, o apoio de sua presença sensível para atravessar a noite, enfrentar a escuridão e a separação.

(Michèle Petit)

Reflexões em torno da leitura literária apresentada por Michèle Petit (2009) fazem ressoar em nós experiências vivenciadas no seio familiar: a avó que lia para os netos sempre no final da tarde para esperar a noite; a mãe leitora que lia romances para si e alimentava o imaginário dos filhos que construíam narrativas fantásticas supostamente a partir do objeto livro, sempre na cabeceira da cama. O livro era para nós um objeto de desejo pelas histórias que guardavam e porque financeiramente era pouco acessível, além de inexistentes as livrarias.

Todas essas memórias evocam ainda o tio contador de histórias que precisava os dias, os nomes, os lugares, as datas de cada narrativa, sempre sentado na cadeira de balanço, chinelos presos aos pés e chapéu sobre as pernas. Eram sempre histórias do lugar, sagas da família e mitos, até então vivos apenas na tradição oral. Líamos pela escuta das "vozes amadas na infância": tio, avó, mãe. Todas essas personagens e experiências leitoras nos fazem pensar, então, sobre quais leitores se constituíram nesse contexto. Essas vivências de leitura, advindas da escuta e da observação atenta nos círculos de leitura familiar, parecem colaborar para a formação de um possível leitor, uma vez que traduzem apropriações do texto de modo singular. Soma-se a essa experiência a vivência em zona rural, de tradição oral, da contação de histórias e causos, do universo fantástico que, para esse grupo de leitores, também sincretizava o religioso e a história de vida. Mas que tipo de leitor se forma a partir da escuta, nos círculos de leitura, nos espaços formais e não formais de leitura?

No âmbito educacional, especificamente no ensino de língua portuguesa, na educação básica, o leitor será construído ao longo da sua escolarização e a depender do contexto socioeconômico que (in)determina o acesso aos livros. Tal conjuntura pode (des)favorecer o desenvolvimento de habilidades de leitura que estejam abertas e despertas para o sensível e estético, podendo ser elaboradas justamente pela atenção à forma, ao modo de construção do texto, aos cruzamentos de leituras no repertório desse sujeito, entre outros elementos que aproximam a produção de significados para o sensível.

Tendo em vista a implicação do leitor mesmo no ato da leitura, na qual se considera seu repertório não apenas de formação educacional formal, mas também suas experiências de vida na compreensão do lido, buscamos em Annie Rouxel (2012a; 2013) compreender o que pressupõe o desenvolvimento de uma leitura e qual o lugar da subjetividade na abordagem do texto literário. As experiências trazidas nos parágrafos iniciais do presente texto dizem de vivências de "leituras cotidianas" que tornavam, para nós (filhos, sobrinhos e netos), naquele contexto, possibilidades de sentidos subjetivos na leitura. Annie Rouxel (2013) compreende que há a leitura subjetiva quando 
Um leitor construído pelas experiências de leituras fundadoras - eu ousaria dizer "arcaicas"? - leituras da infância que permanecem ativas na leitura que dizemos privada ("a criança que lê em nós" de que fala Picard), leituras exatamente solidárias com o diálogo interfantasmático instaurado nas obras, leituras de intenso investimento afetivo que são testemunho de gostos heteróclitos quando, conforme Walter Benjamim, nós "desencaixotamos [nossa] biblioteca", leituras que levam as marcas do desenvolvimento de uma personalidade, dos encontros da vida.... (ROUXEL, 2013, p. 29-30)

Crescer entre histórias narradas por sujeitos reais, sensíveis, e sempre diante dos olhos de meninas que ainda nem frequentavam a escola, por exemplo, pode contribuir para a formação do gosto pela leitura? Ouvir histórias pela voz do tio, da avó e da mãe, nesses momentos fundadores da subjetividade, pode impregnar progressivamente a necessidade de construir sentidos para a leitura? Nasce aí um leitor, um sujeito seduzido para aquilo que só a linguagem é capaz de produzir? Arriscamo-nos a defender que, impregnado pelos efeitos do que ouve, pode o sujeito desenvolver o gosto pela efabulação, que vai se encontrar, mais tarde, como implicado na obra lida (ROUXEL, 2012b, p.281), lugar na leitura dos textos impressos em papel ou outros suportes mais contemporâneos nos quais a literatura se abriga. Ao falar de um "ousar ler a partir de si”, Rouxel (2018, p. 22) trata de uma prática de leitura na qual sujeito e objeto literário são (co)construtores do sentido, sendo que o primeiro está implicado naquilo que lhe é mais íntimo, pessoal, de vivência e experiência, na relação com a literatura: "O que está em causa é sua relação com a linguagem e com a literatura. Esta, aqui, não deve mais ser apreendida do exterior como um monumento a admirar; ela se torna uma prática ativa, um exercício do pensamento envolvido com a vida".

Nas práticas escolares de aprendizagem da leitura literária, a ideia de um sujeito que também se constitui a partir da relação com os textos, tendo em vista uma perspectiva da leitura como humanizadora, conforme debate Antônio Candido (1995), não parece ganhar tanto espaço, já que os movimentos de construção de sentido devem sempre partir do leitor "em formação" que mobiliza um aparato analítico para compreender determinado texto. A literatura, nesse sentido, constitui-se como exterioridade, fora do campo de experiência do leitor. A partir das considerações sobre o ensino de literatura na educação básica e no ensino superior, Rouxel (2012a, p. 20) fala do desafio de ensinar os estudantes a "ler a partir de si mesmos", assumindo nas práticas pedagógicas a subjetividade no campo da leitura literária, encorajando "o leitor a ir mais a fundo em si mesmo de modo a descobrir seu próprio pensamento; na aventura interpretativa, é preciso ter coragem de se aventurar não apenas no desconhecido do texto, mas no desconhecido que está em nós mesmos".

As experiências de leitura descritas inicialmente e aquelas mobilizadas para a escrita deste artigo nos convocaram a "reencontrar o eco longínquo de uma voz ressonante na infância" e, a partir delas, refletir sobre a (des)continuidade dessas experiências como prática de linguagem em sala, na escola, afinal: "Ninguém espera que se aprenda a tocar um instrumento musical se não se exercita com ele" (COLOMER, 2007, p. 65). Além disso, nem todos possuem tais experiências de leitura, sobretudo por pertencerem à sociedade brasileira, que é precariamente alfabetizada, com pais e mães desenvolvendo outras performances, a exemplo daqueles das classes trabalhadoras, especificamente inseridos em dinâmicas sociais que não viabilizam vivências literárias, sejam através do texto escrito ou oral. Ter pais e avós, uma família que se reúne e lê, conta histórias e fortalece os vínculos através dessas práticas, tudo isso não representa a realidade de grande parte de crianças e adolescentes brasileiros. É, portanto, somente na escola que a maioria das crianças terá acesso à leitura de literatura e é pela voz da professora ou professor que ouvem as primeiras histórias, os primeiros versos.

Melo e Silva (2018) tratam, ao considerarem a formação de futuros professores de literatura, do "leitor atrapalhado", que se configura por vivenciar o pouco contato com o literário e, ainda mais, 
pelos raros momentos de mediação que poderiam despertar o gosto sensível. Em contraposição a essa formação que é fomentada desde a tenra infância, com estórias fantásticas, contos de fadas, entre outros, favorecedores de uma recepção estética do literário nas subjetividades dos sujeitos, o "leitor atrapalhado", que é esse do possível, do ler mesmo nas condições pouco favoráveis a uma retenção e ao deleite do estético, também é encontrado nos espaços de ensino, tanto entre os estudantes quanto no corpo docente.

Nesse sentido, pensando nesse leitor "fora do jogo", um leitor que não dispõe de livros em casa e que tem pouco ou nenhum acesso a estes na escola, discutimos a formação do leitor. Focalizamos um leitor que não precisa renunciar a si mesmo em busca de uma pretensa intepretação objetiva, e que suas "experiências de leitura” encontram lugar na escola, nas práticas de leitura literária. É preciso, pois, conceber a leitura literária como lugar de formação de um "sujeito ativo" e que se configura como "experiência intensa cuja abordagem fenomenológica ilumina o fato de que ela não depende apenas dos afetos, mas engaja todo o ser do leitor: seu psiquismo, seu corpo, seu intelecto” (ROUXEL, 2012a, p. 16-17).

Partindo dessas evocações afetivas dadas pela identificação com a obra ficcional, instigadas, inicialmente, pela leitura de Petit (2009), Rouxel (2012a; 2012b; 2013; 2018) e Colomer (2007), e considerando a escola como lugar consagrado à leitura de literatura, propomos aqui pensar sobre o modo como se lê ou se pode ler na escola. Para tanto, tendo em vista colaborar com a prática do professor, bem como pensar sistematicamente nos modos de promover a leitura do texto literário em sala de aula, este trabalho está organizado em duas partes.

$\mathrm{Na}$ primeira parte, analisamos as habilidades que compõem o campo artístico-literário do componente Língua Portuguesa a serem desenvolvidas pelos estudantes do $6^{\circ}$ ao $9^{\circ}$, durante toda a segunda etapa do Ensino Fundamental, segundo os princípios da Base Nacional Comum Curricular (BNCC), (BRASIL, 2017), com o objetivo de analisar como (ou se) tais habilidades promovem a leitura literária como direito à literatura em sala de aula e apontam para práticas de formação de leitores e leitoras.

Na segunda parte, mobilizamos o conto “A Menina de Lá”, de Guimarães Rosa, numa tentativa de apontar possibilidades de experiências estéticas para fruição literária. A escolha do conto se deu pela identificação das autoras, tida aqui como "experimentação complexa do vivido ficcional” (ROUXEL, 2012a, p. 16), tecida com a personagem Nhinhinha, que evocou a figura mística das curandeiras e benzedeiras, ainda presentes na tradição do extremo norte do Tocantins, na memória dos seus habitantes. Além da identificação com a personagem do conto e a obra em si, “[v]amos à ficção para tentar compreender, para conhecer algo mais acerca de nossas contradições, nossas misérias e nossas grandezas, ou seja, acerca do mais profundamente humano" (ANDRUETTO, 2012, p. 54).

\section{O Currículo Escolar e o Direito À Leitura Literária}

Ler é vital para o imaginário.

(Michèle Petit)

Concebemos a leitura como algo necessário à nossa experiência humana na subjetividade, possibilitando a própria compreensão do que somos e do que é ou pode ser o encontro com o outro. O estético nos convoca para a maneira como a interação com o mundo e com o outro nos afeta e nos transforma, tanto pelo que evoca quanto pelo modo como o faz, mediante invenções e subversões da linguagem.

Ao tratarmos de uma formação literária que prepare estudantes para experiência sensível a partir da leitura de literatura, estamos considerando a escola como esse espaço propiciador do contato estético, seja pela dinâmica que põe em operação em suas práticas de ensino, seja por ser considerada uma das habilidades a serem desenvolvidas na disciplina de língua portuguesa. Evocamos aqui, pontualmente, as 
considerações da semiótica de linha francesa, teoria que se ocupa da significação dos textos e do modo como o sentido é construído e constituído nos objetos semióticos, para discutirmos sobre a experiência estética, tendo em vista a interação dos sujeitos leitores com os objetos literários diversos. Inicialmente, ao tratar de uma pedagogia do gosto da leitura, Fiorin (2004, p. 108) assevera que a "sensibilidade não é um dom inato, mas uma habilidade que se desenvolve", ou seja, para que se torne um sujeito sensível à estesia, ao prazer pela leitura, o leitor deve ter condições para apreender as qualidades estéticas daquilo que se põe em contato, a partir de um processo formativo.

Essa formação, no entanto, não pode se repousar estritamente no campo do saber técnico, quando se instrumentaliza o sujeito com um conjunto de habilidades linguísticas e literárias, por exemplo, a fim de reconhecer operações com a língua, estilos, etc. Conforme destaca Tatit (1997), o nível do saber precisa repercutir no nível do sentir, passando da significação meramente ao sentido sensível, tendo em vista uma competência leitora que permita àquele que lê estar "à espera do inesperado" (GREIMAS, 2002), sendo afetado pela experiência do contato com o literário. Sem isso, com o saber resvalando o sentir sensível, o conhecimento técnico pode, inclusive, escamotear o estético, pois o sujeito se poria a submeter os objetos literários ao conjunto de classificações linguísticas e literárias, rejeitando aquilo que pretensamente escapa ao previamente estabelecido. Embora tais práticas e saberes sejam observáveis, ao focalizar a formação de leitores na escola, entendemos que é necessária a união entre saber e sentir, entre ser instrumentalizado com um conhecimento técnico e pô-lo em operação para desvelar ainda mais o campo do literário, com abertura para a estesia. Sem o imbricamento dessas dimensões da leitura, do cognoscível e do sensível, não haveria espaço para a emergência da leitura subjetiva, conforme já discutimos anteriormente.

Ao retornarmos às contribuições dos estudos literários, encontramos em Calvino (2007), na discussão sobre os clássicos da literatura, a reflexão sobre a conexão entre o saber e o (saber) sentir. Segundo o teórico, na análise de uma das obras abordadas, "quando também você encontra a explicação dos fatos, nem por isso os fatos deixam de ser maravilhosos" (CALVINO, 2007, p. 46). Nesse sentido, o conhecimento, e aqui estamos focalizando aquele desenvolvido no percurso da educação básica, do aspecto estético dos objetos pode proporcionar aos sujeitos uma abertura ainda maior à apreciação, ao afetar-se pelos textos literários.

Diante disso, tratamos aqui de reflexões acerca do ensino de leitura no contexto escolar, de acordo com o que preconiza a BNCC (BRASIL, 2017), visando analisar as habilidades que contemplam a leitura literária na escola. Buscamos observar se, considerando o que está expresso no documento, há efetivas orientações para docentes quanto à formação de leitores e leitoras durante a segunda fase do Ensino Fundamental, na educação básica.

O Ensino Fundamental, nesse documento, está organizado em 5 áreas do conhecimento: Linguagens, Matemática, Ciências da Natureza, Ciências Humanas e Ensino Religioso. Todo o currículo está aparelhado de forma a desenvolver as 10 competências gerais, nas quais estão alinhadas as competências de cada área do conhecimento e, por conseguinte, as competências de cada componente curricular (disciplina):

Ao longo da Educação Básica, as aprendizagens essenciais definidas na BNCC devem concorrer para assegurar aos estudantes o desenvolvimento de dez competências gerais, que consubstanciam, no âmbito pedagógico, os direitos de aprendizagem e desenvolvimento. (BRASIL, 2017)

As aprendizagens essenciais de cada componente curricular estão organizadas de modo a convergir para práticas de ensino interdisciplinares e que, fundamentalmente, devem desenvolver os princípios da 
igualdade, diversidade e equidade. Assim, as competências gerais da $\mathrm{BNCC}^{2}$ preveem a formação integral de estudantes e professores. Alinhado às competências gerais, o componente Língua Portuguesa definiu dez competências específicas. Num recorte que pretende enfatizar as competências de leitura, selecionamos as competências 1, 3, 4, 7, 8 e 9, que tratam da língua como fenômeno cultural, histórico e social, e da prática de leitura literária como prática de formação de leitores e leitoras, nos seguintes termos:

1. Compreender a língua como fenômeno cultural, histórico, social, variável, heterogêneo e sensível aos contextos de uso, reconhecendo-a como meio de construção de identidades de seus usuários e da comunidade a que pertencem. [...]

3. Ler, escutar e produzir textos orais, escritos e multissemióticos que circulam em diferentes campos de atuação e mídias, com compreensão, autonomia, fluência e criticidade, de modo a se expressar e partilhar informações, experiências, ideias e sentimentos, e continuar aprendendo.

4. Compreender o fenômeno da variação linguística, demonstrando atitude respeitosa diante de variedades linguísticas e rejeitando preconceitos linguísticos. [...]

7. Reconhecer o texto como lugar de manifestação e negociação de sentidos, valores e ideologias.

8. Selecionar textos e livros para leitura integral, de acordo com objetivos, interesses e projetos pessoais (estudo, formação pessoal, entretenimento, pesquisa, trabalho etc.).

9. Envolver-se em práticas de leitura literária que possibilitem o desenvolvimento do senso estético para fruição, valorizando a literatura e outras manifestações artístico-culturais como formas de acesso às dimensões lúdicas, de imaginário e encantamento, reconhecendo o potencial transformador e humanizador da experiência com a literatura. (BRASIL, 2017, p. 87)

Sinteticamente, as referidas competências concebem a língua como "fenômeno cultural, social, variável, heterogêneo e sensível" e o texto como "lugar de manifestação e negociação de sentidos, valores e ideologias". Na prática, esses conhecimentos devem ser desenvolvidos através das práticas de linguagem ou eixos (oralidade/escuta, produção (escrita e multissemiótica) e análise linguística/semiótica). Quanto à leitura, é tratada em sentido amplo e tem como suporte o "texto escrito", "imagens estáticas e em movimento", e o "som" (BRASIL, 2017). É ainda compreendida nas dimensões inter-relacionadas às práticas de uso e reflexão em práticas leitoras e práticas de produção de textos.

Dizem respeito às práticas leitoras, de acordo com o documento: a reconstrução e reflexão sobre as condições de produção e recepção dos textos pertencentes a diferentes gêneros que circulam nas diferentes mídias e esferas/campos de atividade humana; a dialogia e relação entre textos; a reconstrução da textualidade, recuperação e análise da organização textual, da progressão temática e estabelecimento de relações entre as partes do texto; a reflexão crítica sobre as temáticas tratadas e validade das informações; a compreensão dos efeitos de sentido provocados pelos usos de recursos linguísticos e multissemióticos em textos pertencentes a gêneros diversos; estratégias e procedimentos de leitura; adesão às práticas de leitura. Cabe, ainda, às práticas de produção de textos considerar e refletir sobre os seguintes aspectos: as condições de produção dos textos que regem a circulação de diferentes gêneros nas diferentes mídias e campos de atividade humana, dialogia e relação entre textos, alimentação temática, construção da textualidade, aspectos notacionais e gramaticais, e estratégias de produção (BRASIL, 2017, p. 72-80).

Todo esse esboço é uma tentativa de delinear de modo mais didático o que está proposto para o ensino de leitura, sobretudo, a leitura de literatura na BNCC. Vejamos o que está proposto para essa prática de linguagem/eixo "leitura":

${ }^{2}$ Adotaremos a sigla BNCC para otimizar a leitura e referência a Base Nacional Comum Curricular. 
O Eixo Leitura compreende as práticas de linguagem que decorrem da interação ativa do leitor/ouvinte/ espectador com os textos escritos, orais e multissemióticos e de sua interpretação, sendo exemplos as leituras para: fruição estética de textos e obras literárias [grifo nosso]; pesquisa e embasamento de trabalhos escolares e acadêmicos; realização de procedimentos; conhecimento, discussão e debate sobre temas sociais relevantes; sustentar a reivindicação de algo no contexto de atuação da vida pública; ter mais conhecimento que permita o desenvolvimento de projetos pessoais, dentre outras possibilidades. (BRASIL, 2017, p. 71)

As bases conceituais fundadoras do componente Língua Portuguesa sinalizam a participação ativa do estudante e a leitura como experiência estética. Trazem a obra literária como objeto/suporte para as práticas de linguagem dentro do campo artístico-literário, relativo ao conjunto de práticas voltadas para dimensões formativas e usos da linguagem, que reúnem as habilidades a serem desenvolvidas, progressivamente, ao longo da educação básica. Observa-se, inicialmente, que, embora a BNCC contemple a leitura como "fruição estética de textos e obras literárias", o contato com o estético está estritamente relacionado à produção de significação para o lido. Nesse sentido, parece haver o apagamento do sentido sensível e da leitura subjetiva, uma vez que relaciona a fruição estética à habilidade de desvendar os modos como os textos se constituem e significam. Se o modo de interagir com os textos literários se restringe à evocação de categorias de significação pretensamente objetivas, que são aprendidas e apreendidas através de uma formação escolar, pode não acontecer o favorecimento de formação de um "sujeito capaz de eleger as próprias categorias de análise do texto, de lançar um olhar subjetivo, de fazer emergir novas significações para o lido" (REIS; AMORIM; MELO, 2017, p. 77).

As habilidades que compõem o componente Língua Portuguesa a serem desenvolvidas durante os anos finais somam 181 habilidades. Dentre elas, apenas 13 contemplam, explicitamente, o texto literário ora como prática de leitura/escuta ora como produção de texto ou análise linguística/semiótica. É esse apagamento da literatura ou sua tímida expressão no currículo que empreendemos refletir agora. Analisar todas as habilidades demandaria um trabalho mais extenso e de longo prazo. Por isso, focalizamos, a seguir, apenas três habilidades, que deverão ser mobilizadas na análise do conto "A menina de lá", apresentada na terceira parte deste trabalho.

Tomamos, portanto, as habilidades 33, 44 e 53, as duas primeiras a serem desenvolvidas no $8^{\circ} \mathrm{e}$ $9^{\circ}$ anos, e as últimas no $6^{\circ}$ ao $9^{\circ}$ ano. Vejamos:

EF89LP33) ${ }^{3}$ Ler, de forma autônoma, e compreender - selecionando procedimentos e estratégias de leitura adequados a diferentes objetivos e levando em conta características dos gêneros e suportes romances, contos contemporâneos, minicontos, fábulas contemporâneas, romances juvenis, biografias romanceadas, novelas, crônicas visuais, narrativas de ficção científica, narrativas de suspense, poemas de forma livre e fixa (como haicai), poema concreto, ciberpoema, dentre outros, expressando avaliação sobre o texto lido e estabelecendo preferências por gêneros, temas, autores. (BRASIL, 2017, p. 187)

(EF69LP44) Inferir a presença de valores sociais, culturais e humanos e de diferentes visões de mundo, em textos literários, reconhecendo nesses textos formas de estabelecer múltiplos olhares sobre as identidades, sociedades e culturas e considerando a autoria e o contexto social e histórico de sua produção. (BRASIL, 2017, p. 157)

\footnotetext{
${ }^{3}$ Cada letra e número situam na etapa de ensino, ano/série, componente curricular e número da habilidade. Pode-se ler, detrás para frente, como forma de dar mais sentido ao código ou para facilitar a sua memorização. A exemplo, lê-se: Habilidade 33, referente ao componente Língua Portuguesa a ser desenvolvida no $6^{\circ}$ e $7^{\circ}$ anos do Ensino Fundamental (EF67LP33).
} 
(EF69LP53) Ler em voz alta textos literários diversos - como contos de amor, de humor, de suspense, de terror; crônicas líricas, humorísticas, críticas; bem como leituras orais capituladas (compartilhadas ou não com o professor) de livros de maior extensão, como romances, narrativas de enigma, narrativas de aventura, literatura infantojuvenil, - contar/recontar histórias tanto da tradição oral (causos, contos de esperteza, contos de animais, contos de amor, contos de encantamento, piadas, dentre outros) quanto da tradição literária escrita, expressando a compreensão e interpretação do texto por meio de uma leitura ou fala expressiva e fluente, que respeite o ritmo, as pausas, as hesitações, a entonação indicados tanto pela pontuação quanto por outros recursos gráfico-editoriais, como negritos, itálicos, caixa-alta, ilustrações etc., gravando essa leitura ou esse conto/reconto, seja para análise posterior, seja para produção de audiobooks de textos literários diversos ou de podcasts de leituras dramáticas com ou sem efeitos especiais e ler e/ou declamar poemas diversos, tanto de forma livre quanto de forma fixa (como quadras, sonetos, liras, haicais etc.), tempregando os recursos linguísticos, paralinguísticos e cinésicos necessários aos efeitos de sentido pretendidos, como o ritmo e a entonação, o emprego de pausas e prolongamentos, $\mathrm{o}$ tom e o timbre vocais, bem como eventuais recursos de gestualidade e pantomima que convenham ao gênero poético e à situação de compartilhamento em questão. (BRASIL, 2017, p. 161)

Introduzidas sempre por verbos como analisar, inferir, posicionar, engajar, elaborar, ler e criar, as habilidades que contemplam o texto literário convocam os estudantes e os professores para a "reconstrução das condições de produção, circulação e recepção", "apreciação e réplica", "reconstrução da textualidade e compreensão dos efeitos de sentidos provocados pelos usos de recursos linguísticos e multissemióticos", "consideração das condições de produção", "estratégias de produção: planejamento, textualização e revisão/edição”. Sem a pretensão de invalidar a importância dessas práticas de uso e reflexão da língua, chamamos a atenção para o fato de que, embora o texto literário seja o objeto/suporte de algumas práticas, a fruição literária, o sensível parece ter lugar impreciso ou quase inexistente. Parecenos que as práticas focalizam precisamente a decodificação, a formação de um sujeito que saiba ler, apenas, e não precisamente a de leitor competente. Tais objetivos são válidos e necessários à educação formal e ao ensino de língua e literatura, porém, há de se considerar o lugar para o sensível, para a produção do sentido subjetivo mediante aquilo que se lê. Ao tratar de uma “educação literária”, Teresa Colomer (2017) destaca a necessidade de aproximação entre um conhecimento técnico, formal, que instrumentalize as crianças e adolescentes a conhecerem e reconhecerem as produções literárias e culturais de seu povo, e uma habilidade estética para a apreciação sensível daquilo que se lê, de modo a formar esses sujeitos.

Nessa perspectiva, as situações de aprendizagem devem promover experiências que mobilizem o conhecimento em suas diversas formas sem suprimir as subjetividades, o sensível. Em Colomer (2007), essa necessidade fica evidente quando afirma a indissolubilidade entre formar sujeitos a partir da convivência ativa sustentada na interação entre pessoas, entre pessoas e textos. Afinal,

Ao poder poético e secreto de um livro se acrescenta um outro interesse, que é esperar compreender como os significados impostos pela leitura são transgredidos ou, ainda, como a invenção - a do autor ou do leitor - se vê sempre refreada por aquilo que impõem as capacidades, as normas e os gêneros. Contra a visão simplista que supõe servidão dos leitores quanto às mensagens impostas (ou lidas!), pode-se lembrar que a recepção é criação, e o consumo, produção, levando a insistir que toda a criação, toda apropriação de sentidos, está relacionada às condições de possibilidade historicamente variáveis e socialmente desiguais... (CUNHA, 2014, p. 43) 
A escola, para muitos, é o único lugar de acesso à literatura. Portanto, conceber o ensino de leitura literária na escola como lugar de formação de leitores e leitoras está para além da leitura instrumentalizada. É preciso que formemos sujeitos capazes de codificar e decodificar, mas, sobretudo, de transgredir, como afirma Cunha (2014), mesmo em face às condições socialmente desiguais a que estamos submetidos. Para muitos estudantes, é o livro didático o único livro ao seu alcance e passível de acesso. Além disso, a biblioteca escolar, quando existe, tem acervo tímido e/ou espaço pouco favorável para práticas de leitura. Diante desse panorama, a sala de aula passa a ser o lugar privilegiado para se ler. Decorre daí, portanto, a necessidade de que essa leitura promova a "produtividade" e que os textos ofereçam, pois, a possibilidade de os estudantes exercerem as suas capacidades (CUNHA, 2014, p. 45).

\section{Breve Olhar Sobre "A menina de lá"}

O conto "A menina de lá" compõe a obra "Primeiras Estórias", do autor João Guimarães Rosa (2005). Selecionamos essa narrativa como objeto literário para análise por considerarmos um texto com características regionalistas e que pode atrair o leitor pelas imagens construídas a partir de cada personagem, assim como do lugar: a relação mítica de sujeitos interioranos com o universo espiritual e religioso. Nele o escritor mobiliza termos como "uruicuiana", que situa o leitor no espaço da narrativa, pois o termo refere-se a quem nasce ou é habitante da cidade de Urucuía, Minas Gerais. Além disso, o texto cria e recria as palavras num processo de (des)construção das formas, sobretudo formas orais, jogando com a oralidade na escrita. Mas que história narra "A menina de lá”?

Como o próprio título sugere, trata-se da história de uma menina de quase 4 anos chamada Maria, a Nhinhinha, que parecia não pertencer a este mundo das sensibilidades ordinárias e mais "terrenas". Nhinhinha morava num lugar chamado "Temor-de-Deus" e "Sua casa ficava para atrás da Serra do Mim". A protagonista do conto nem tinha 4 anos e "nascera já muito para miúda, cabeçudota e com olhos enormes" (ROSA, p. 65). A protagonista da narrativa enxergava para além do que qualquer pessoa podia ver, constituindo-se inteiramente como presença e percepção sensível dos fenômenos que a rodeiam. A menina não tinha brinquedos e fazia dos bichos e outros elementos da natureza personagens imaginários, com quem interagia e mantinha uma relação simétrica com a natureza.

Nhinhinha começou a fazer milagres e o seu pai temeu que a igreja a levasse para um convento, retirando-a do convívio com a família e a comunidade. O conto tematiza a infância e, de certa forma, ilustra o modo como as crianças podem construir símbolos, imaginar, em sua presença sensível no mundo, que é intermediada pelo olhar e interação de ordem mais pragmática e menos afetuosa dos adultos.

Tecido esse breve percurso de leitura acerca do conto "A menina de Lá", lido a priori pela conduta de identificação, destacamos que há outras abordagens que merecem ser consideradas e que analisam o conto na perspectiva do desenvolvimento da infância. Nesse conto, em específico, Guimarães Rosa tematiza a infância e, se olharmos sob a ótica piagetiana, por exemplo, veremos que Nhinhinha apresenta comportamentos típicos da sua idade, da fase pré-lógica. Uma criança com 4 anos tem necessidade de se comunicar e nesse processo constrói símbolos, lugar de manifestação da fantasia. Brincar e interagir fazem parte da atividade representativa, ou seja, a criança tem necessidade e direito "a experiência de vivenciar formas de pensamento por meio da imitação, do simbólico e das representações cognitivas” (SILVA, 2016, p.4).

Poderíamos discutir aqui o insólito no conto (SILVA, 2016), bem como a necessidade e dificuldade na interação pela linguagem (CARNIAL, 2008) que Nhinhinha demonstra, porém, propomos desde o início pensar o ensino de literatura em sala de aula em turmas dos anos finais do ensino fundamental. Para tanto, daremos ênfase ao continum da leitura cotidiana e ao estatuto da leitura literária, uma leitura 
mais aberta na qual os estudantes possam manifestar sua criatividade, dialogar com o mundo do passado e do presente, e (re)significar o ler.

\section{Transposição Didática do Conto “A Menina de LÁ": Problematizações e Perspectivas}

Inicialmente propomos produzir uma atividade de leitura a partir das competências EF89LP33, EF69LP44, EF69LP53, sistematizadas para o componente Língua Portuguesa na BNCC, no eixo leitura, mobilizando o conto "A menina de Lá" de Guimarães Rosa. A primeira habilidade, prevista para ser desenvolvida no $8^{\circ}$ e $9^{\circ}$ ano do ensino fundamental, compõe o campo de experiência "artístico-literário", eixo "leitura", e tem como objeto do conhecimento "Estratégias de leitura" e "Apreciação e réplica". A habilidade desdobra o objeto do conhecimento, propondo que o estudante leia com autonomia e seja capaz compreender o texto se utilizando de "procedimentos e estratégias de leitura adequadas a diferentes objetivos e levando em conta características dos gêneros e suportes...” (BRASIL, 2017, p. 171). Tomando essa competência na sua integridade, percebemos que sua ênfase está na formação de um "leitor-modelo" que dispõe de conhecimentos linguísticos e tem consciência e domínio das estratégias e procedimentos de construção do texto. Trata-se de um leitor capaz de deter-se ao texto pelo texto, apreendendo-o e, a partir do que está expresso no texto, seja capaz de compreender o seu conteúdo. A apreciação, nesse caso, não diz respeito a uma experiência que focalize também o sentir, mas se repousa estritamente ao campo do saber ler, isto é, o cognitivo está sobreposto ao sensível, sem que se traduzam numa necessária relação de complementaridade, como parece indicar alguns processos de ensino de leitura (a hipótese de que o saber ler conduz invariavelmente a um gostar de ler).

A segunda habilidade também compõe o campo "artístico-literário", eixo "Leitura", e traz como objetos do conhecimento "Reconstrução das condições de produção, circulação e recepção" e "Apreciação e réplica". A habilidade propõe que o/a estudante seja capaz de inferir, a partir do objeto literário, "valores sociais, culturais e humanos e de diferentes visões de mundo... reconhecendo nesses textos formas de estabelecer múltiplos olhares sobre as identidades, sociedades e culturas e considerando a autoria e o contexto social e histórico de sua produção" (BRASIL, 2017, 157). Nessa competência, o texto literário parece colaborar para imersões no que diz respeito à existência humana, à lógica social e à construção da identidade individual e coletiva a partir de valores. Ainda assim, não aponta para a leitura literária como continum das experiências de leitura dos estudantes.

A terceira e última habilidade selecionada para análise também compõe o campo "artístico-literário", eixo "Oralidade", e traz como objetos do conhecimento a "Produção de textos orais" e a "Oralização". A habilidade prevê a leitura em voz alta de textos diversos (contos, romances, narrativas de aventura, etc.) e que o estudante seja capaz de expressar a "compreensão e interpretação do texto, que respeite o ritmo, as pausas...empregando recursos linguísticos, paralinguísticos e cinésicos...” (BRASIL, 2017, p. 161).

A oralidade, atividade humana na qual se registra o nascimento da contação de histórias, para muitos, foi e ainda será o primeiro contato com a leitura. Esse "acúmulo de práticas sociais" que a criança reúne e carrega consigo para a escola precisa encontrar lugar num movimento contínuo e, a partir disso, formar-se como pessoa (COLOMER, 2007, p. 52). No entanto, nas habilidades focalizadas, o texto literário é tratado, numa "dimensão do cognoscível”, o que pode conduzir a um ensino de leitura em que o leitor "subtrai do texto apenas o que interessa para alcançar um dado fim [...] o emprego do texto como pretexto para o ensino de gênero, ou de gramática, ou das correntes literárias, ou para o ensino de história etc.” (SILVA; MELO, 2015, p. 128). 
Mas, afinal, qual o objetivo da educação literária?

[...]é, em primeiro lugar, o de contribuir para a formação da pessoa, uma formação que aparece ligada indissoluvelmente à construção da sociabilidade e realizada através da confrontação com textos que explicitam a forma em que as gerações anteriores e as contemporâneas abordaram a avaliação da atividade humana através da linguagem. (COLOMER, 2007, p. 31)

Pensar a transposição didática dos contos fundados na ideia de leitor ideal é reforçar práticas restritas quanto à formação de leitores. É preciso despertar o interesse no/a estudante, prevendo a sua participação e modos de avançar nesse processo de desenvolvimento da leitura literária. A construção do sentido como prática contínua a ser promovida na escola não depende de um momento determinado para "desfrutar da experiência literária. Ao contrário, é a sua participação em um ato completo de comunicação literária o que lhes permite avançar por esse caminho” (COLOMER, 2007, p. 60). Nesse sentido, promover práticas de leitura de modo linear hierarquizando-a nos níveis da compreensão e da intepretação, exclui a possibilidade de construção do sentido pelo estudante na relação leitor-texto/ objeto literário, ao qual se debruça.

Rouxel postula que,

Ainda mais aberta e mais próxima da realidade, a cultura literária que se deseja encorajar é esse espaço simbólico composto ao mesmo tempo de referências pessoais e de referências comuns configuradas pela subjetividade do leitor. Mais liberal e mais empírica, essa concepção de cultura literária não pode ser avaliada por meio de referências legítimas e quantificáveis; ela revela um olhar menos exterior, estando assentada em três noções teorizadas recentemente: o texto do leitor, a interleitura e a biblioteca interior. (ROUXEL, 2012a, p. 18)

Todas essas reflexões acerca das habilidades de leitura sistematizados na BNCC, dentro do eixo leitura e oralidade, problematizadas a partir do arcabouço teórico mobilizado, nos permitiram delinear o que julgamos relevante no ensino de leitura literária. Filiamo-nos às concepções trazidas aqui por crermos que, de fato, o ensino de literatura convoca-nos a abrigar as "referências pessoais" somadas às "referências comuns configuradas pela subjetividade do leitor". As noções de "texto leitor", "interleitura" e "Biblioteca interior", assinaladas no debate teórico sobre a subjetividade, orientam sobre modos de promover a leitura literária em sala de aula, pois, somadas, revelam o ponto alto a que devemos chegar nesse processo: promover uma prática que permita ao estudante se formar leitor, conduzindo-o de modo a manifestar suas experiências de leitura numa relação com o mundo (passado e presente).

Por tudo isso, transpor as habilidades a partir do conto "A menina de Lá" se configurou um desafio, uma vez que, além de não ser um documento didático, A BNCC não prevê os problemas na formação dos professores, seja em nível inicial ou a formação continuada, bem como suas possíveis dificuldades para desdobrar os objetos do conhecimento que estão postos de modo genérico. Algumas propostas são aplicáveis e podem convergir para práticas enriquecedoras no desenvolvimento da leitura literária, sobretudo no trabalho com o gênero conto, como é o exemplo da sequência didática (COSSON, 2006). De antemão, consideramos que a sequência didática tem sido uma opção comum às escolas de educação básica em função do que essa metodologia agrega dentro dos projetos de leitura ou projetos interdisciplinares na escola.

Nesse sentido, optamos por trazer, em forma de proposta, as reflexões de Annie Rouxel (2012a; 2012b; 2013; 2018), que propõe a formação de um leitor "subjetivo". Para isso, a autora definiu 
três prioridades para a formação de uma cultura literária na escola que consiste na "abordagem menos formal do texto, mais sensível", "privilegiar a leitura em ato ao invés do resultado da leitura" e "preferir a noção de espaço intersubjetivo ao conceito de arquileitor”. Dessas prioridades, depreendemos os seguintes passos:

1. Organizar a sala em círculo, preferencialmente, para viabilizar melhor integração entre estudantes e professora/or;

2. Disponibilizar o conto completo "A menina de lá" a todos os estudantes;

3. Ler o conto com ou para os estudantes, em sala, sem pressa e se deixando contagiar pela leitura;

4. Após a leitura, "dar espaço aos textos dos alunos". A ideia é que sejam textos orais nos quais os alunos possam dizer das suas impressões sobre o texto, sobre Nhinhinha ou aspectos não previstos pela professora ou professor, sejam elas consistentes ou não. A professora ou professor deve gerenciar o tempo de fala dos estudantes e escutar atentamente o que dizem sobre o conto;

5. Encorajar ao máximo a participação ativa dos estudantes, mediando as falas sempre que necessário. Se necessário, algumas perguntas podem ajudar nesse processo de leitura e que se voltam para as vozes da narrativa: Quem (personagens)? Onde (espaço)? Quando (tempo)? Ou, ainda, solicitar que façam recortes do texto para contextualizar a sua fala. É necessário também "aceitar a ideia do mal-entendido" e reconhecer esse esforço como parte do procedimento interpretativo;

6. Ainda em círculos, promover as trocas mediante objeto literário lido, pois essa prática pode permitir ampliar a leitura em aspectos não observados pelos estudantes durante o ato de leitura;

7. Adotando o procedimento da metacognição: "conhecimento que o sujeito tem sobre o seu próprio conhecimento", mediar caso ocorra algum "erro de leitura";

8. Tornar a sala um espaço onde os estudantes possam se envolver e manifestar suas leituras individuais, favorecendo, assim, a "reflexão coletiva". Nessa relação de manifestação intersubjetiva, podem tecer novas ou manter as leituras feitas mediante o conto "A menina de lá";

9. Debater com os estudantes as motivações para interpretações que não se encontram respaldadas na materialidade textual. Esse momento de mediação é importante porque favorece o desenvolvimento de habilidade de leitura a partir dos próprios equívocos na interpretação. É importante não rechaçar pura e simplesmente alguns caminhos de leitura, já que o olhar sensível de cada sujeito pode conduzi-lo a direções diversas, inclusive para fora do texto;

10. Permitir que os estudantes relatem suas experiências de leitura mediante o texto lido;

11. Acolher e valorizar as experiências de leitura dos estudantes;

12. Encorajar os estudantes a produzirem um "diário de leitura" como forma de registrarem o seu percurso de leitor literário, as impressões mediante textos lidos e se fazem associações na forma de intertextualidades ou interleituras;

13. Caso os estudantes perguntem e demonstrem interesse sobre o autor, apresentar o autor e a obra.

\section{Considerações Finais}

Nascido de nossas inquietações advindas da experiência docente e como formadoras de professores nesse processo de apropriação da BNCC, este artigo se lança como uma experiência inicial no percurso que se quer construir de pensar o ensino de leitura literária na escola. A BNCC demorou quase 
10 anos tramitando até a sua aprovação. É um documento que nasce da necessidade e expectativa dos docentes em ter um currículo nacional comum com vistas a possibilitar a todas os estudantes brasileiros o acesso e o desenvolvimento dos seus direitos de aprendizagens.

Em contrapartida, em virtude dos conflitos políticos instaurados no país nos últimos quatro anos, a política nacional de formação de professores foi bastante comprometida, deixando os professores à margem no que diz respeito à apropriação e à transposição da BNCC para a prática pedagógica. Cientes do desinvestimento na educação pública nacional, lançamo-nos ao desafio de colaborar com os professores que atuam no ensino de literatura na escola, fazendo um recorte teórico que julgamos importante e que trata da formação do leitor literário na escola. Neste trabalho, no entanto, focalizamos alguns limites em relação ao ensino de leitura literária, tendo em vista as orientações curriculares em voga. Além disso, selecionamos o conto "A menina de lá” de Guimarães Rosa por considerar que sua obra trata de aspectos que vão ao encontro de experiências de vida e de leitura dos estudantes.

Nesse sentido, buscamos em Annie Rouxel, que mobiliza outros teóricos do campo do ensino de literatura, uma perspectiva de ensino de leitura literária em sala de aula. Vale ressaltar que o que propomos não traduz todo cerne do debate desenvolvido pela autora, mas representa um esforço nosso na tentativa de compreender e promover a cultura literária na escola, que é o de encorajar a participação ativa, a manifestação das subjetividades do estudante, acolher, reconhecer e valorizar as experiências de leituras dos estudantes.

\section{REFERÊNCIAS}

ANDRUETTO, Maria Teresa. Por uma literatura sem adjetivos. Trad: Carmem Cacciacarro. São Paulo: Editora Pulo do Gato, 2012.

BRASIL. Base Nacional Comum Curricular. Brasília: MEC, 20017. Disponível em: http:/ basenacionalcomum.mec.gov.br/images/BNCC_20dez_site.pdf. Acesso em: 12 de abril de 2020.

CALVINO, Italo. Por que ler os clássicos. Trad. Nilson Moulin. São Paulo: Companhia das Letras, 2007.

CANDIDO, Antonio. Direito à literatura. In: Vários escritos. São Paulo: Duas Cidades, 1995.

CARNIAL, Luciana. A palavra transformadora em "A menina de lá”. Kalíope, São Paulo, ano 4, n. 2, p. jul./dez., 2008.

COLOMER, Tereza. Andar entre livros: a leitura literária na escola. Trad. Laura Sandroni. São Paulo: Global, 2007.

COSSON, Rildo. Letramento literário: teoria e prática. São Paulo: Contexto, 2006.

CUNHA, Betina. Leitura e Literatura no Mundo da Escola. Revista Literatura em Debate. V. 8, n. 15, p. 42-51, dez. 2014.

FIORIN, José Luiz. Linguística e pedagogia da leitura. Scripta, v. 7, n. 14, 2004, p. 107-117.

GREMIAS, Algirdas Julien. Da Imperfeição. Trad. Ana Claudia de Oliveira. São Paulo: Hacker Editores, 2002.

HOUAISS. Dicionário Eletrônico Houaiss da Lingua Portuguesa. Rio de Janeiro: Objetiva, 2009. 
MELO, Márcio Araújo de; SILVA, Luiza Helena Oliveira da. O leitor atrapalhado e a formação docente. Revista Brasileira de Literatura Comparada, n. 35, 2018, p. 63-75.

PETIT, Michèle. $A$ arte de ler ou como resistir à diversidade. Trad.: Arthur Bueno e Camila Boldroni. São Paulo: Ed. 34, 2009.

REIS, Naiane Vieira; AMORIN, Eduardo; MELO, Márcio Araújo de. Entre Leitores e Literatura: formação literária em As palavras, de Jean-Paul Sartre. Revista Entreletras (Araguaína), v.8, n.1, p. 76-88). jan./jun. 2017.

ROSA, João Guimarães. Primeiras estórias. Especial. Rio de Janeiro: Nova Fronteira, 2005. P. 65-69.

ROUXEL, Annie. Mutações epistemológicas e o ensino da literatura: o advento do sujeito leitor. Revista Criaşão \& Crítica (USP), n. 9, p. 13-24, 2012a. Disponível em http:/ /www.revistas.usp.br/ criacaoecritica/article/view/46858. Acesso em: 23 de abril de 2020.

ROUXEL, Annie. Práticas de leitura: quais rumos para favorecer a expressão do sujeito leitor? Trad.

Neide L. de Rezende e Gabriela R. de Oliveira. Cadernos de pesquisa, v. 42, n. 145, $2012 \mathrm{~b}$.

ROUXEL, Annie; LANGLADE, Gérard; REZENDE, Neide Luzia de (org.). Leitura Subjetiva e ensino de literatura. São Paulo: Alameda, 2013.

ROUXEL, Annie. Ousar ler a partir de si: desafios epistemológicos, éticos e didáticos da leitura subjetiva. Trad. Rosiane Xypas. Revista Brasileira de Literatura Comparada, n. 35, 2018.

SILVA, Luiza Helena de Oliveira. Leitura subjetiva e a formaşão do leitor na escola. Mimeo, 2020.

SILVA, Luiza Helena Oliveira da. MELO, Márcio Araújo de. O que pode o leitor?. Revista Entreletras (Araguaína/TO), v. 6, n. 2, jul/dez. 2015.

SILVA, Tânia Regina Silva da Silva. O insólito no conto "A menina de lá", de Guimarães Rosa. XII Semana de Extensão, Pesquisa e Pós-Graduação SEPesq, Out. 2016, Centro Universitário Ritter dos Reis.

TATIT, Luiz. Questões do gosto no Banquete de Mário de Andrade. In: LANDOWSKI, Eric; FIORIN, José Luiz (Orgs.). O gosto da gente, o gosto das coisas: abordagem semiótica. São Paulo: EDUC, 1997, p. 47-60. 